\title{
Karakterisasi, Kesesuaian Lahan dan Teknologi Kelapa Sawit Rakyat di Rawa Pasang Surut Kalimantan Tengah
}

\section{Characteristic of Land Suitability and Farmer Oil Palm Technology in Tidal Swamp of Central Kalimantan}

\author{
M. Anang Firmansyah \\ Balai Pengkajian Teknologi Pertanian Kalimantan Tengah \\ Jl. G. Obos km 5 Palangka Raya \\ Email: anang.firmansyah75@yahoo.com; HP:081352738525
}

\begin{abstract}
Oil palm extensification in tide land. It's a marginal land which sensitive to degradation. Otherwise, peat is low bearing capacity, subsidence, drying irreversible and close fire and then emission of green house gas. So other soil in the tide land is acid sulfate soils have a pyrite, while be can oxidation can produce of increased soil acidity and ferro and aluminum. Location of research include ine Ex Rice Mega Project ie. Kapuas Regency and Pulang Pisau Regency, and other is East Kotawaringin Regency. Limiting factor in soil mineral are effective dept of soil and drainage class (S3-d2.s2 dan s2-d2); and then in peatland are soil dept, decomposition factor and drainage class (S3-t2.d2, S3-s2d2 dan S3-d2). Agronomic action used farmer and plantation industry very variance, so characteristic and climate quality, land, agronomic, post harvest wil can level of agronomic compound of oil palm in tide land wich better for produce, efficiency, and green environment.
\end{abstract}

Keywords: Oil palm, tidal swamp, Central Kalimantan

Diterima: 17-02-2014, disetujui: 02-05-2014

\section{PENDAHULUAN}

Tanaman Kelapa sawit (Elaeis guineensis Jacq) merupakan tanaman yang memiliki sebaran adaptasi cukup luas, dapat tumbuh pada berbagai agroekosistem dengan baik dan memberikan potensi produksi yang optimal mulai dari tanah-tanah di lahan kering (Ultisol, Inceptisol, Oxisol) hingga tanah-tanah yang berkembang di agroekosistem rawa pasang surut (Gambut, sulfat masam).

Umumnya pengembangan tanaman kelapa sawit oleh perusahaan besar yang membuka untuk kebun inti dan plasma terletak di lahan kering. Data luasan kebun kelapa sawit di Kalimantan Tengah tahun 2009 sebesar 909.703 ha, 3 besar antara lain Kabupaten Kotawaringin 
Timur seluas 344.433 ha, Kabupaten Seruyan seluas 210.122 ha, dan Kabupaten Kotawaringin Barat seluas 155.490 ha (BPS Kalimantan Tengah, 2010).

Total luasan daerah pasang surut di Kalimantan Tengah sebesar 2,8791 juta hektar (Tim Swamp-II). Sedangkan menurut BB Litbang SDLP, 2008 dalam Agus dan Subiksa 2008) mengungkapkan bahwa luasan gambut di Kalimantan Tengah sebesar 3,01 juta hektar. Lahan rawa pasang surut dapat dibedakan berdasarkan tipologi luapan air pasang dan drainasenya, yaitu tipe A, B, C, dan D. Sedangkan berdasarkan jenis tanahnya lahan pasang surut terbagi menjadi: potensial, gambut, dan sulfat masam.

Pada berbagai kajian menunjukkan bahwa tanah yang tergenang di kebanyakan tahun dengan sifat aquic (sulfat masam) dan juga gambut tergolong memiliki kelas kesesuaian lahan aktual sesuai marjinal (S3) hingga tidak sesuai (N1) dengan status kesuburan rendah, namun memiliki potensi produksi hingga 22-30 t TBS/ha/th (Adiwiganda et al. dalam Koedadiri et al., 1999).

Lahan pasang surut umumnya terdiri dari jenis tanah gambut dan tanah sulfat masam. Tanah gambut adalah tanah yang terdiri dari bahan organik lebih dari 20-30\%, dengan kendala utama drainase buruk, daya sangga tanah yang rendah, penurunanan permukaan tanah, kandungan hara relatif rendah, tingginya $\mathrm{Fe}, \mathrm{Al}$, dan $\mathrm{S}$, serta kemasaman yang tinggi akibat asam-asam organik yang bersifat meracun terhadap perakaran tanaman. Sedangkan tanah sulfat masam (aktual/potensial) selain memiliki drainase buruk juga tingkat kemasaman tinggi akibat adanya lapisan pirit. Kemasaman yang tinggi dengan $\mathrm{pH}<3$ akan menjadi kendala berat bagi pertumbuhan tanaman kelapa sawit.

Pembuatan saluran drainase yang lebar dan dalam untuk mengatus air rawa agar rawa kering dan sekaligus pembuatan guludan sistim surjan dengan tujuan tercipta zona perakaran cukup dalam untuk perakaran kelapa sawit telah mengakibatkan lapisan pirit teroksidasi yang mengeluarkan sulfat sehingga tanah menjadi masam. Menurut Aribawa et al. (1993) pembuatan guludan pada lahan sulfat masam akan menurunkan $\mathrm{pH}$ tanah, meningkatkan konsentrasi besi, aluminium, dan sulfat. Pada lahan gambut dampak pembuatan drainase ini menyebabkan air rawa menjadi surut, permukaan air tanah menurun, gambut mengering, menimbulkan bahaya kebakaran, selain itu meningkatkan emisi gas rumah kaca. Menurut Rieley et al., (2008 dalam Las et al., 2011) lahan gambut kondisi hutan alami memiliki emisi $30 \mathrm{t} \mathrm{CO}_{2} / \mathrm{ha} / \mathrm{th}$, sedangkan jika didrainase sedalam $60 \mathrm{~cm}$ maka emisi meningkat menjadi $55 \mathrm{t} \mathrm{CO}_{2} / \mathrm{ha} / \mathrm{th}$.

Tujuan dari penelitian ini adalah untuk karakterisasi lahan pasang surut yang digunakan untuk perkebunan kelapa sawit rakyat dan menyusun rakitan teknologi budidaya kelapa sawit di agroekosistem pasang surut tingkat petani di Kalimantan Tengah.

\section{METODE}

Penelitian dilakukan mulai bulan Mei-Oktober 2012. Lokasi penelitian di perkebunan kelapa sawit milik rakyat di agroekosistem pasang surut yaitu Kecamatan Lamunti di Kabupaten Kapuas, Kecamatan Maliku di Kabupaten Pulang Pisau, dan Kecamatan Mentaya Hilir Utara di Kabupaten Kotawaringin Timur.

Kondisi lahan pasang surut yang umumnya memiliki genangan ataupun muka air tanah dangkal bahkan lapisan sulfidik diketahui dengan mengukur mikrotopografi pada kondisi tanah mineral maupun tanah gambut pewakil. Kondisi pewakil untuk tanah mineral dilakukan di 
M. Anang Firmansyah:Karakterisasi, Kesesuaian Lahan dan Teknologi Kelapa Sawit Rakyat...

Kabupaten Pulang Pisau sedangkan untuk tanah gambut dilakukan di Kabupaten Kotawaringin Timur.

Klasifikasi kesesuaian lahan untuk kelapa sawit yang tumbuh di tanah mineral maupun tanah gambut yang disurvai pada lokasi penelitian, mengacu pada kriteria kesesuaian lahan untuk kelapa sawit di tanah mineral dan tanah gambut (Tabel 1 dan 2).

Tabel 1. Kriteria Kesesuaian Lahan untuk Kelapa Sawit pada Tanah Mineral

\begin{tabular}{|c|c|c|c|c|c|c|}
\hline \multirow{2}{*}{ No. } & \multirow{2}{*}{ Karakteristik Lahan } & \multirow{2}{*}{ Simbol } & \multicolumn{4}{|c|}{ Intensitas Faktor Pembatas } \\
\hline & & & Tanpa (0) & Ringan (1) & Sedang (2) & Berat (3) \\
\hline 1 & Curah Hujan (mm) & $\mathrm{h}$ & $1.750-3.000$ & $\begin{array}{c}1.750-1.500 \\
>3.000\end{array}$ & $1.500-1.250$ & $<1.250$ \\
\hline 2 & $\begin{array}{l}\text { Bulan kering }(<60 \\
\mathrm{mm})\end{array}$ & $\mathrm{k}$ & $<1$ & $1-2$ & $2-3$ & $>3$ \\
\hline 3 & Ketinggian (dpl m) & 1 & $0-200$ & 200-300 & $300-400$ & $>400$ \\
\hline 4 & $\begin{array}{l}\text { Bentuk wilayah/ } \\
\text { kemiringan lereng } \\
(\%)\end{array}$ & $\mathrm{w}$ & $\begin{array}{l}\text { Datar- } \\
\text { Berombak } \\
\quad<8\end{array}$ & $\begin{array}{l}\text { Berombak- } \\
\text { bergelombang } \\
8-15\end{array}$ & $\begin{array}{c}\text { Bergelombang- } \\
\text { Berbukit } \\
15-30\end{array}$ & $\begin{array}{l}\text { Berbukit- } \\
\text { Bergunung } \\
\quad>30\end{array}$ \\
\hline 5 & $\begin{array}{l}\text { Batuan dipermukaan } \\
\text { dan didalam tanah } \\
(\% \mathrm{v})\end{array}$ & $\mathrm{b}$ & $<3$ & $3-15$ & $15-40$ & $>40$ \\
\hline 6 & $\begin{array}{l}\text { Kedalaman efektif } \\
(\mathrm{cm})\end{array}$ & $\mathrm{s}$ & $>100$ & $100-75$ & $75-50$ & $<50$ \\
\hline 7 & Tekstur tanah & $\mathrm{t}$ & $\begin{array}{l}\text { Lempung } \\
\text { Berdebu, } \\
\text { Lempung Liat } \\
\text { Berpasir, } \\
\text { Lempung Liat } \\
\text { Berdebu, } \\
\text { Lempung } \\
\text { Berliat }\end{array}$ & $\begin{array}{l}\text { Liat, Liat } \\
\text { Berpasir, } \\
\text { Lempung } \\
\text { Berpasir, } \\
\text { Lempung }\end{array}$ & $\begin{array}{l}\text { Pasir } \\
\text { Berlempung, } \\
\text { Debu }\end{array}$ & $\begin{array}{l}\text { Liat Berat, } \\
\text { Pasir }\end{array}$ \\
\hline 8 & Kelas drainase & $d$ & Baik, Sedang & $\begin{array}{l}\text { Agak } \\
\text { terhambat, } \\
\text { Cepat }\end{array}$ & $\begin{array}{l}\text { Cepat, } \\
\text { Terhambat }\end{array}$ & $\begin{array}{c}\text { Sangat } \\
\text { Cepat, } \\
\text { Sangat } \\
\text { Terhambat, } \\
\text { Tergenang }\end{array}$ \\
\hline 9 & $\begin{array}{l}\text { Kemasaman tanah } \\
(\mathrm{pH})\end{array}$ & a & $5,0-6,0$ & $\begin{array}{l}4,0-5,0 \\
6,0-6,5\end{array}$ & $\begin{array}{l}3,5-4,0 \\
6,5-7,0\end{array}$ & $\begin{array}{l}<3,5 \\
>7,0 \\
\end{array}$ \\
\hline
\end{tabular}

Tabel 2. Kriteria Kesesuaian Lahan untuk Kelapa Sawit pada Tanah Gambut

\begin{tabular}{|c|c|c|c|c|c|c|}
\hline \multirow[t]{2}{*}{ No. } & \multirow[t]{2}{*}{ Karakteristik Lahan } & \multirow[t]{2}{*}{ Simbol } & \multicolumn{4}{|c|}{ Intensitas Faktor Pembatas } \\
\hline & & & Tanpa (0) & Ringan (1) & Sedang (2) & Berat (3) \\
\hline 1 & Curah Hujan (mm) & $\mathrm{h}$ & $1.750-3.000$ & $\begin{array}{c}1.750-1.500 \\
>3.000\end{array}$ & $1.500-1.250$ & $<1.250$ \\
\hline 2 & Bulan kering $(<60 \mathrm{~mm})$ & $\mathrm{k}$ & $<1$ & $1-2$ & $2-3$ & $>3$ \\
\hline 3 & Ketinggian (dpl m) & 1 & $0-200$ & $200-300$ & $300-400$ & $>400$ \\
\hline 4 & $\begin{array}{l}\text { Kandungan bahan kasar } \\
(\% \mathrm{v})\end{array}$ & $\mathrm{b}$ & $<3$ & 3-15 & $15-40$ & $>40$ \\
\hline 5 & Ketebalan Gambut $(\mathrm{cm})$ & $\mathrm{s}$ & $0-60$ & $60-150$ & $150-300$ & $>300$ \\
\hline 6 & $\begin{array}{l}\text { Tingkat pelapukan } \\
\text { gambut }\end{array}$ & $\mathrm{t}$ & Saprik & $\begin{array}{l}\text { Hemosaprik, } \\
\text { Saprohemik }\end{array}$ & $\begin{array}{c}\text { Hemik, } \\
\text { Fibrohemik, } \\
\text { Hemofibrik }\end{array}$ & Fibrik \\
\hline 7 & Kelas drainase & d & - & - & Terhambat & $\begin{array}{c}\text { Sangat } \\
\text { Terhambat, } \\
\text { Tergenang }\end{array}$ \\
\hline 8 & Kemasaman tanah $(\mathrm{pH})$ & $\mathrm{a}$ & $5,0-6,0$ & $4,0-5,0$ & $3,5-4,0$ & $<3,5$ \\
\hline
\end{tabular}


Jurnal Penelitian Pertanian Terapan

Sedangkan klasifikasi kesesuaian lahan untuk tanaman kelapa sawit (Tabel 3). Analisis akan dilakukan secara tabulasi maupun matching menggunakan faktor pembatas (limiting factor) antara parameter yang telah disusun sebelumnya secara desk study dengan hasil survai dan pengambilan contoh dari lokasi penelitian.

Tabel 3. Klasifikasi Kesesuaian Lahan untuk Tanaman Kelapa Sawit

\begin{tabular}{ll}
\hline \multicolumn{1}{c}{ Kelas Kesesuaian Lahan } & \multicolumn{1}{c}{ Kriteria } \\
\hline S1(Sangat Sesuai) & $\begin{array}{l}\text { Unit lahan yang memiliki tidak lebih dari satu pembatas } \\
\text { ringan (optimal) } \\
\text { Unit lahan yang memiliki lebih dari satu pembatas ringan } \\
\text { dan/atau tidak memiliki lebih dari satu pembatas sedang. }\end{array}$ \\
S3 (Agak Sesuai) & $\begin{array}{l}\text { Unit lahan yang memiliki lebih dari satu pembatas sedang } \\
\text { dan/atau tidak memiliki lebih dari satu pembatas berat. }\end{array}$ \\
N1 (Tidak Sesuai Bersarat) & $\begin{array}{l}\text { Unit lahan yang memiliki dua atau lebih pembatas berat yang } \\
\text { masih dapat diperbaiki. }\end{array}$ \\
N2 (Tidak Sesuai Permanen) & $\begin{array}{l}\text { Unit lahan yang memiliki pembatas berat yang tidak dapat } \\
\text { diperbaiki. }\end{array}$ \\
\hline
\end{tabular}

Sumber: Buana et al. (2003).

Data primer yang diperlukan adalah sifat fisik maupun kimia tanah melalui pengambilan contoh tanah utuh maupun komposit. Parameter untuk menyusun rakitan teknologi kelapa sawit rakyat terdiri dari tipologi luapan, umur tanaman, persiapan bibit, persiapan lahan dan tanam, pemupukan, pemeliharaan dan pemanenan.. Data sekunder meliputi data iklim dan data produksi.

\section{HASIL DAN PEMBAHASAN}

\section{Kondisi Curah Hujan}

Curah hujan merupakan salah satu karakteristik lahan yang penting bagi pertumbuhan dan produksi tanaman kelapa sawit. Kondisi curah hujan yang kurang dari $1.250 \mathrm{~mm} /$ tahun tergolong faktor penghambat intensitas berat, sedangkan untuk sedang antara $1.500-1.250 \mathrm{~mm} / \mathrm{th}$, ringan 1.750-1500 atau $>3.000 \mathrm{~mm} / \mathrm{th}$, dan tanpa pembatas bantara 1.750-3.000 mm/th.

Data curah hujan di lokasi survai yaitu Kabupaten Kapuas curah hujan rata-rata bulanan dari tahun 2001 - 2011; data curah hujan di Kabupaten Pulang Pisau di gunakan curah hujan ratarata bulanan periode 1997-2011; dan data curah hujan di lokasi Kabupaten Kotawaringin Timur digunakan periode 1983-2011 (Gambar 1).

Gambar 1. Kondisi curah hujan rata-rata bulanan di Kabupaten Kapuas, Pulang Pisau dan Kotawaringin Timur. 
M. Anang Firmansyah:Karakterisasi, Kesesuaian Lahan dan Teknologi Kelapa Sawit Rakyat...

\section{Kondisi Tanah Sulfat Masam}

Berdasarkan survai dan karakteristik lahan kelapa sawit yang ditanam masyarakat dan telah berbuah pasir ditemukan di wilayah pasang surut Kabupaten Kapuas dan Kabupaten Pulang Pisau terdapat kandungan pirit $\left(\mathrm{FeS}_{2}\right)$ pada lapisan tanahnya.

Tanah Sulfat Masam tergolong Potensial karena ditemukan lapisan pirit yang terukur pada kedalaman $>50 \mathrm{~cm}$, di lokasi Kapuas lapisan pirit terdeteksi pada $53 \mathrm{~cm}$, sedangkan di Kabupaten Pulang Pisau lapisan pirit terletak pada kedalaman $102 \mathrm{~cm}$ hingga $45 \mathrm{~cm}$ dengan muka air tanah antara $35 \mathrm{~cm}$ dan makin dalam mencapai $106 \mathrm{~cm}$ saat mendekati saluran tersier. Lapisan tanah gambut kurang dari $50 \mathrm{~cm}$, umunyaa kebakaran yang berulang-ulang akibat pembuatan saluran drainase menyebabkan lapisan gambut cenderung menipis dan habis. Kondisi $\mathrm{pH}$ air saluran kwarter mencapai 4, pH air saluran tersier 4,5, dan $\mathrm{pH}$ air permukaan tanah kebun 4,5.

Kondisi lapisan pirit dan muka air tanah di Desa Gandang Barat, Kecamatan Maliku, Kabupaten Pulang Pisau menunjukkan bahwa kedalaman pirit dan lapisan muka air tanah yang berhimpit, bahkan pada posisi mendekati saluran tersier (Gambar 2).

Gambar 2. Mikro topografi lapisan gambut, air, bahan sulfidik dan tanah mineral dari saluran tersier $(0 \mathrm{~m})$ hingga mendekati saluran kuarter $(90 \mathrm{~m})$ di kebun kelapa sawit rakyat, Kecamatan Maliku, Kabupaten Pulang Pisau.

Nampak lapisan pirit sudah diatas lapisan muka air tanah akan memicu terjadinya proses oksidasi pirit yang dapat memasamkan tanah. Guna mengamankan lapisan pirit melalui peningkatan muka air tanah tidak memungkinkan dipasang pintu air atau ditabat karena saluran tersebut digunakan sebagai sarana angkutan lalu lintas air.

Kondisi dangkalnya lapisan pirit pada tanah yang digunakan penanaman kelapa sawit $(<$ $150 \mathrm{~cm}$ tanah mineral atau $<200 \mathrm{~cm}$ tanah gambut) sangat rawan terhadap proses oksidasi yang menyebabkan tanah akan menjadi sangat masam. Kedalaman lapisan pirit pada lokasi sampling yang $<150 \mathrm{~cm}$ menunjukkan zona kedalaman untuk perkembangan perakaran tanaman sawit yang tidak aman. Menurut Rahutomo dan Sutarta (2001) pengembangan kelapa sawit pada tanah sulfat masam yang kedalaman lapisan pirit $<150 \mathrm{~cm}$ jika pirit terletak dibawah tanah mineral atau 200 $\mathrm{cm}$ jika pirit terletak di bawah tanah gambut digolongkan sebagai lahan yang tidak layak dikembangkan sebagai areal perkebunan kelapa sawit. 
Jurnal Penelitian Pertanian Terapan

\section{Kondisi Tanah Gambut}

Kondisi tanah gambut ditemukan di Kecamatan Maliku, Kabupaten Pulang Pisau, maupun di Kecamatan Mentaya Hilir Selatan di Kabupaten Kotawaringin Timur. Kondisi tanah gambut di Lokasi Kabupaten Kotawaringin Timur berjarak kurang lebih 7 km dari Sungai Mentaya memiliki ketebalan gambut 149-210 cm dengan subsoil tanah mineral pasir kuarsa. Tingkat kematangan gambut dilahan kebun kelapa sawit rakyat tergolong telah matang (Saprik) dan lapisan subsoil disusun oleh pasir kuarsa serta tidak dijumpai lapisan pirit. Kondisi pasir kuarsa ini kurang menunjang bagi kesesuaian lahan untuk tanaman kelapa sawit. Pasir kuarsa yang ditemukan di dasar lapisan gambut diduga berasal dari batuan pasir. Menurut Graha (1987) kuarsa merupakan mineral umum dan terjadi dalam perbedaan yang besar dari lingkungan geologi, juga banyak ditemukan batu pasir terutama batu pasir kuarsa. Brady (1990) kuarsa umumnya mendominasi fraksi pasir yang resisten terhadap pelapukan dan memiliki aktivitas kimia rendah.

Mikrotopografi menunjukkan bahwa ketebalan gambut bervariasi namun cenderung menebal searah makin menjauh dari saluran tersier, begitu pula dengan lapisan subsoil pasir kuarsa (Gambar 3).

Gambar 3. Mikro topografi permukaan air, gambut dan sub soil pasir kuarsa dimulai dari saluran tersier $(0 \mathrm{~m})$ hingga mendekati saluran kuarter $(55 \mathrm{~m})$ di kebun kelapa sawit rakyat, Kecamatan Mentaya Hilir Utara, Kabupaten Kotawaringin Timur.

\section{Kelas Kesesuaian Lahan Tanaman Kelapa sawit}

Curah hujan di ketiga lokasi kabupaten survai (Kapuas=2.133 mm/th, Pulang Pisau=1.881 $\mathrm{mm} / \mathrm{th}$, dan Kotawaringin Timur=2.972 mm/tah) nampaknya bukan kendala, karena masuk kedalam kisaran 1.750-3.000 mm/th yang cukup baik menunjang ketersediaan air bagi tanaman kelapa sawit. Begitu halnya dengan tidak memiliki bulan kering pada lokasi survai, merupakan factor penunjang pengembangan kebun kelapa sawit. Dilihat dari ketinggian lahan di daerah survai dikisaran $0-200 \mathrm{~m}$ dpl, maka lokasi kebun yang terletak pada ketinggian 1-6,5 m tergolong bukan kendala untuk pengembangan kelapa sawit. Begitu pula bentuk wilayah yang datar bukan kendala bagi pengembangan tanaman kelapa sawit.

Kendala untuk tanah mineral sulfat masam terdeteksi sedang pada $53-83 \mathrm{~cm}$, padahal kedalaman efektif yang diinginkan untuk pengembangan kelapa sawit $>100 \mathrm{~cm}$. Begitu juga dengan kelas drainase yang terhambat merupakan kendala sedang untuk pengembangan kelapa sawit. 
M. Anang Firmansyah:Karakterisasi, Kesesuaian Lahan dan Teknologi Kelapa Sawit Rakyat...

Guna mengetahui kelas kesesuaian lahan untuk kelapa sawit, maka digunakan kriteria PPKS baik untuk tanah mineral maupun tanah gambut (Tabel 2-3).

Tabel 2. Karakteristik Lahan Kelapa Sawit Rakyat di Lokasi Penelitian

\begin{tabular}{|c|c|c|c|c|c|c|}
\hline \multirow{3}{*}{ No. } & \multirow{3}{*}{ Karakteristik Lahan } & \multirow{3}{*}{ Simbol } & \multicolumn{4}{|c|}{ Intensitas Faktor Pembatas Lahan Kelapa Sawit Rakyat } \\
\hline & & & \multirow{2}{*}{$\begin{array}{c}\text { Kapuas } \\
\text { TSMP }\end{array}$} & \multicolumn{2}{|c|}{ Pulang Pisau } & \multirow{2}{*}{$\frac{\text { Kotawaringin Timur }}{\text { TG }}$} \\
\hline & & & & TSMP & TG & \\
\hline 1 & Curah Hujan (mm) & $\mathrm{h}$ & $2.133,2$ & $1.881,0$ & $1.881,0$ & $2.972,1$ \\
\hline 2 & Bulan kering $(<60 \mathrm{~mm})$ & $\mathrm{k}$ & 0 & 0 & 0 & 0 \\
\hline 3 & Ketinggian (dpl m) & 1 & 1 & 6 & 6 & 3,5 \\
\hline 4 & $\begin{array}{l}\text { Bentuk wilayah/ } \\
\text { kemiringan lereng (\%) }\end{array}$ & $\mathrm{W}$ & $\begin{array}{c}\text { Datar } \\
<3 \%\end{array}$ & $\begin{array}{l}\text { Datar } \\
<3\end{array}$ & $\begin{array}{l}\text { Datar } \\
<3 \%\end{array}$ & Datar \\
\hline 4 & $\begin{array}{l}\text { Kandungan bahan kasar } \\
(\% \text { v) Gambut }\end{array}$ & $\mathrm{b}$ & - & - & 2 & 2 \\
\hline 5 & Ketebalan Gambut (cm) & s & - & - & 100 & 210 \\
\hline 6 & Tingkat pelapukan gambut & $\mathrm{t}$ & - & - & Hemofibrik & Hemosaprik \\
\hline 5 & $\begin{array}{l}\text { Batuan dipermukaan dan } \\
\text { didalam tanah (\%v) }\end{array}$ & $\mathrm{b}$ & 0 & 0 & - & - \\
\hline 6 & Kedalaman efektif (cm) & $\mathrm{s}$ & 53 & 83 & 40 & 50 \\
\hline 7 & Tekstur tanah & $\mathrm{t}$ & Liat & Liat & - & - \\
\hline 8 & Kelas drainase & $\mathrm{d}$ & terhambat & terhambat & terhambat & terhambat \\
\hline 9 & Kemasaman tanah $(\mathrm{pH})$ & $\mathrm{a}$ & 4 & 4 & 4 & 4 \\
\hline
\end{tabular}

Keterangan TSMP $=$ Tanah Sulfat Masam Potensial, $\mathrm{TG}=$ Tanah Gambut.

Tabel 3. Klasifikasi Kelas Kesesuaian Aktual Lahan Kelapa Sawit Rakyat di Lokasi Penelitian

\begin{tabular}{|c|c|c|c|c|c|c|}
\hline \multirow{3}{*}{ No. } & \multirow{3}{*}{ Karakteristik Lahan } & \multirow{3}{*}{ Simbol } & \multicolumn{4}{|c|}{ Intensitas Faktor Pembatas Lahan Kelapa Sawit Rakyat } \\
\hline & & & \multirow{2}{*}{$\begin{array}{c}\text { Kapuas } \\
\text { SMP }\end{array}$} & \multicolumn{2}{|c|}{ Pulang Pisau } & \multirow{2}{*}{$\frac{\text { Kotawaringin Timur }}{\mathrm{G}}$} \\
\hline & & & & SMP & $\mathrm{G}$ & \\
\hline 1 & Curah Hujan (mm) & $\mathrm{h}$ & 0 & 0 & 0 & 0 \\
\hline 2 & Bulan kering $(<60 \mathrm{~mm})$ & $\mathrm{k}$ & 0 & 0 & 0 & 0 \\
\hline 3 & Ketinggian (dpl m) & 1 & 0 & 0 & 0 & 0 \\
\hline 4 & $\begin{array}{l}\text { Bentuk wilayah/ } \\
\text { kemiringan lereng }(\%)\end{array}$ & $\mathrm{W}$ & 0 & 0 & 0 & 0 \\
\hline 4 & $\begin{array}{l}\text { Kandungan bahan kasar } \\
(\% \text { v) Gambut }\end{array}$ & $\mathrm{b}$ & & & & \\
\hline 5 & Ketebalan Gambut (cm) & $\mathrm{s}$ & - & - & 1 & 2 \\
\hline 6 & $\begin{array}{l}\text { Tingkat pelapukan } \\
\text { gambut }\end{array}$ & + & - & - & 2 & 1 \\
\hline 5 & $\begin{array}{l}\text { Batuan dipermukaan dan } \\
\text { didalam tanah }(\% \mathrm{v})\end{array}$ & $\mathrm{h}$ & 0 & 0 & 0 & 0 \\
\hline 6 & Kedalaman efektif $(\mathrm{cm})$ & S & 2 & 1 & - & - \\
\hline 7 & Tekstur tanah & $\mathrm{t}$ & 1 & 1 & - & - \\
\hline 8 & Kelas drainase & d & 2 & 2 & 2 & 2 \\
\hline 9 & Kemasaman tanah $(\mathrm{pH})$ & a & 1 & 1 & 1 & 1 \\
\hline & KKL & & $\mathrm{S} 3-\mathrm{d} 2 . \mathrm{s} 2$ & $\mathrm{~S} 2-\mathrm{d} 2$ & $\mathrm{~S} 3-\mathrm{t} 2 . \mathrm{d} 2$ & $\mathrm{~S} 3-\mathrm{s} 2 \mathrm{~d} 2$ \\
\hline
\end{tabular}

Keterangan SMP = Sulfat Masam Potensial, G = Tanah Gambut. 
Jurnal Penelitian Pertanian Terapan

Kendala pada tanah gambut terdeteksi pada ketebalan gambut yang lebih dari atau sama dengan $60 \mathrm{~cm}$, sedangkan rata-rata ketebalan kebun kelapa sawit di Pulang Pisau dan Kotawaringin Timur antara $90-210 \mathrm{~cm}$. Begitu pula kelas drainase yang terhambat merupakan kendala tingkat sedang.

\section{Teknologi Budidaya Kelapa Sawit Tingkat Petani}

Rakitan teknologi budidaya kelapa sawit di lahan pasang surut meliputi teknologi budidaya kelapa sawit tingkat rakyat, ternyata sebagian telah menerapkan tahapan budidaya yang termasuk rekomendasi tentang budidaya kelapa sawit oleh PPKS (Tabel 4).

Hal penting yang ditemukan adalah pada mutu bibit kelapa sawit, para petani mengaku bahwa bibit kelapa sawit berasal dari Marihat yang ditawarkan oknum pedagang dengan menunjukkan foto copy sertifikat, namun ada juga petani yang mengaku bibit kelapa sawit yang ditanam tidak jelas. Hal ini rawan karena terkait dengan banyaknya tersebar bibit palsu.

Tabel 4. Rakitan Teknologi Budidaya Kelapa Sawit di Lahan Pasang Surut di Kalimantan Tengah pada Tingkat Petani Rakyat

\begin{tabular}{|c|c|c|c|c|}
\hline \multirow{2}{*}{\multicolumn{2}{|c|}{ Aspek Teknologi Budidaya }} & \multicolumn{3}{|c|}{ Kabupaten } \\
\hline & & Kapuas & Pulpis & Kotim \\
\hline A. & Tipe Luapan & $\mathrm{C} / \mathrm{D}$ & $\mathrm{C} / \mathrm{D}$ & $\mathrm{C} / \mathrm{D}$ \\
\hline B. & Umur Tanaman & 13 bulan & 30 bulan & 36 bulan \\
\hline \multirow{8}{*}{ C. } & Persiapan Bibit & & & \\
\hline & a. Varietas benih & Marihat & Marihat & Tidak Jelas \\
\hline & b. Umur bibit & 13 bulan & 12 bulan & 8 bulan \\
\hline & c. Asal/sertifikasi benih & Pelaihari & Pangkalan Bun & Sampit \\
\hline & d. Persemaian awal & Ada & Tidak ada & Tidak ada \\
\hline & e. Persemaian akhir & Ada & Ada & Tidak ada \\
\hline & f. Pemberian amelioran dan pupuk & Ada & Ada & Tidak ada \\
\hline & g. Pengendalian OPT & Ada & Ada & Tidak ada \\
\hline \multirow[t]{7}{*}{ D. } & Persiapan Lahan dan Tanam & & & \\
\hline & a. Pembukaan dengan bakar & Tidak ada & Dilakukan & Dilakukan \\
\hline & b. Pembukaan tanpa bakar & Herb\&Traktor & Herbisida & Tebas \\
\hline & c. Pemancangan dan jarak tanam & Ada & Ada & Ada \\
\hline & d. Pembuatan lubang tanam & Ada & Ada & Ada \\
\hline & e. Jarak tanam & $8 \times 9 \mathrm{~m}$ & $9 \times 9 \mathrm{~m}$ & $7 \times 9 \times 9 \mathrm{~m}$ \\
\hline & f. Adanya saluran drainase & Ada & Ada & Ada \\
\hline \multirow{4}{*}{ E. } & Pemupukan & & & \\
\hline & a. Amelioran & Ada & Ada & Tidak ada \\
\hline & b. Jenis pemupukan & Org/Anorg & Org/Anorg & Anorganik \\
\hline & c. Frekuensi pemupukan & 6 kali & 7 kali & 6 kali \\
\hline \multirow[t]{3}{*}{ F. } & Pemeliharaan & & & \\
\hline & a. Kastrasi Bunga & - & Ada & Ada \\
\hline & b. Pengendalian OPT & - & Ada & Ada \\
\hline \multirow[t]{5}{*}{ G. } & Pemanenan & & & \\
\hline & a. Pembuangan buah pasir & - & Ada & Ada \\
\hline & b. Penyisaan pelepah sangga 2 & - & - & Belum \\
\hline & c. Penjualan TBS & - & - & $2-4 \mathrm{~kg} / \mathrm{TBS}$ \\
\hline & d. Penjualan Total & - & - & $1-2 \mathrm{t} / 3 \mathrm{ha}$ \\
\hline
\end{tabular}

Keterangan: SMP = Sulfat Masam Potensial, TBM=Tanaman Belum Menghasilkan, TM=Tanaman Meghasilkan, OPT=Organisme Pengganggu Tanaman, TBS=Tandan Buah Segar. 
M. Anang Firmansyah:Karakterisasi, Kesesuaian Lahan dan Teknologi Kelapa Sawit Rakyat...

\section{KESIMPULAN}

Lahan yang ditanami masyarakat untuk kelapa sawit tidak dipilih kesesuaian lahannya, yang utama adalah luasan kepemilikan lahannya sendiri, dengan keyakinan bahwa kelapa sawit yang mereka tanam akan berproduksi. Rakitan teknologi kelapa sawit rakyat di lahan pasang surut beragam antara petani. Kendala utama pengembangan kelapa sawit di lahan pasang surut pada tanah mineral di tingkat sedang adalah kedalaman efektif tanah dan kelas drainase, sedangkan di tanah gambut adalah ketebalan gambut, tingkat kematangan gambut, dan kelas drainase.

\section{DAFTAR PUSTAKA}

Agus, F., dan I. G. M Subikse. 2008. Lahan gambut: potensi untuk pertanian dan aspek lingkungan.

Aribawa, I. B., S. Suping, K. Nugroho, dan I. P. G Widjaja Adhi. 1993. Perubahan redoks potensial dan kimia tanah guludan pada tanah sulfat masam di Kalimantan Selatan. Pembr. Pen. Tanah dan Pupuk No. 11. 18-26.

BPS Kalteng 2010. Kalimantan Tengah dalam Angka 2010.

Brady, N.C. 1990. The nature and propertis of soils. Tenth Edition. Macmillan Publishing Company. New York. 621 hal.

Buana, L., D. Siahaan, dan S. Adiputra. 2003. Modul M-100-203. Kultur Teknis Kelapa sawit, penilaian kesesuaian lahan, disain kebun dan pembukaan lahan. Pusat Penelitian Kelapa Sawit. Medan. Hal:1-9.

Graha, D. S. 1987. Batuan dan mineral. Penerbit Nova. Bandung. 259 hal.

Koedadiri A. D., W. Darmosarkoro, dan E. S. Sutarta. 1999. Potensi dan pengelolaan tanah ultisol pada beberapa wilayah perkebunan kelapa sawit di Indonesia. Konggres Nasional VII HITI, Bandung 2-4 Nopember 1999.

Las, I., P. Setyanto., K. Nugroho, A. Mulyani., dan F. Agus. 2011. Perubahan iklim dan pengelolaan klahan gambut berkelanjutan. BBSDLP. Bogor. 24 hal.

Rahutomo, S dan E. S. Sutarta. 2001. Kendala budidaya kelapa sawit pada tanah sulfat masam. Warta PPKS. 9(1):9-15.

Tim Swamps-II. 1991. Pertanian lahan pasang surut dan rawa di Sumatera Selatan. Potensi, kendala dan prospek pengembangannya. Badan Litbang Pertanian.

Winarna, E. S. Sutarta, dan Sugiyono. 2007. Kesatuan contoh daun dan sistem pengambilan contoh daun. Warta PPKS. 15(2):25-32. 